\title{
Generation of Humanized Zebrafish Models for the In Vivo Assessment of Antisense Oligonucleotide-Based Splice Modulation Therapies
}

\author{
Renske Schellens, Erik de Vrieze, Ralph Slijkerman, Hannie Kremer, \\ and Erwin van Wijk
}

\begin{abstract}
Antisense oligonucleotide (AON)-based splice modulation is the most widely used therapeutic approach to redirect precursor messenger RNA (pre-mRNA) splicing. To study the functional effect of human mutations affecting pre-mRNA splicing for which $\mathrm{AON}$-based splice redirection would be a potential therapeutic option, humanized knock-in animal models are pivotal. A major limitation of using humanized animal models for this purpose is the reported poor recognition of human splice sites by the splicing machineries of other species. To overcome this problem, we provide a detailed guideline for the generation of functional humanized knock-in zebrafish models to assess the effect of mutation-induced aberrant splicing and subsequent AON-based splice modulation therapy.
\end{abstract}

Keywords Pre-mRNA splicing, Species-specific minigene splice assay, Antisense oligonucleotides, Inherited retinal dystrophies, Usher syndrome, Zebrafish

\section{Introduction}

Precursor messenger RNA (pre-mRNA) splicing is a tightly regulated and complicated process. The spliceosome, a multicomponent protein complex, removes introns from the pre-mRNA by recognizing and joining each splice donor site, located at the $5^{\prime}$ end of the intron, to its corresponding splice acceptor site, located at the $3^{\prime}$ end of the intron. The remaining exons are subsequently fused together to form mature mRNA. However, genetic variants in both introns and exons can affect the process of splicing and result in a range of pathogenic phenotypes.

For inherited retinal dystrophies (IRDs), it has been estimated that $\sim 20 \%$ of all identified mutations affect pre-mRNA splicing [1]. Numerous of those mutations have already been described in literature $[2-4]$, of which the recurrent deep-intronic 
c.7595-2144A $>\mathrm{G}$ mutation in $U S H 2 A$ intron 40 is an example [5]. This mutation creates a strong splice donor site resulting in the incorporation of a pseudoexon (PE40) into all USH2A transcripts and as a consequence, the premature termination of usherin translation. Loss of usherin function in man results in either combined hearing and vision loss (Usher syndrome) or non-syndromic vision loss (retinitis pigmentosa).

Currently, the most widely used approach to interfere with premRNA splicing is antisense oligonucleotide (AON)-based splice modulation. AONs are small single-stranded RNA molecules designed complementary to their target pre-mRNA. Upon binding to splicing regulatory elements within the pre-mRNA transcript, AONs are capable of correcting aberrant pre-mRNA splicing, inducing the skipping of (pseudo)exons or promoting the inclusion of native exons [6].

Humanized animal models, in which a specific part of the species' genomic DNA is replaced by the orthologous human sequence, are pivotal to study the functional effect of aberrant splicing and AON-based splice correction therapy. Multiple vertebrate model organisms, each having their pros and cons, are currently being used for IRD-associated translational research purposes. Among those, the zebrafish represents a fast and inexpensive model which has proven its strength in studying IRDs. Zebrafish are easy to genetically manipulate, have a retinal structure comparable to humans, and for most IRDs (including Usher syndrome) robust phenotypes can already be detected at 5 days post fertilization (dpf) [7].

A major difficulty of using humanized knock-in animal models for the purpose of studying aberrant splicing and evaluating AON-based splice correction is the reported poor recognition of human splice sites by the splicing machineries of other species $[8,9]$. As such, thorough in silico bio-informatic analyses and in vitro cell-based splice assays are essential for the development of a humanized animal model that properly recognizes the splice sites of the introduced human sequence. In this chapter, we will discuss the step-by-step procedure to generate functional humanized zebrafish models, including optimization in cross-species splice-site recognition, to assess the effect of mutation-induced aberrant splicing and subsequent $\mathrm{AON}$-based splice redirection therapies.

\section{Materials}
2.1 In Silico Splice
1. A computer with internet access and a web browser. Site Analysis 
2.2 Cloning of a Minigene Splice Vector

1. Forward and reverse primers including attB tails to generate a Gateway ${ }^{\circledR}$ cloning-compatible PCR amplicon containing the (pseudo)exon of interest flanked by $>500$ bp up- and downstream intronic sequence (see Notes 1 and 2 ).

2. Gel and PCR Clean-up kit.

3. Gateway ${ }^{\circledR} \mathrm{BP}$ clonase enzyme mix (Thermo Fisher scientific, Carlsbad (CA), USA).

4. Gateway ${ }^{\circledR}$ LR clonase enzyme mix (Thermo Fisher scientific, Carlsbad (CA), USA).

5. Gateway ${ }^{\circledR}$ pDONR201 vector (Thermo Fisher scientific, Carlsbad (CA), USA).

6. A pCI-neo-based zebrafish-specific minigene splice assay destination vector [9].

7. DH5 $\alpha$ competent cells.

8. LB agar plates: Dissolve $20 \mathrm{~g} \mathrm{NaCl}, 20 \mathrm{~g}$ tryptone, and $10 \mathrm{~g}$ yeast extract into $750 \mathrm{ml}$ water. Add $30 \mathrm{~g}$ agar and fill up to 11 . Autoclave the medium and let it cool down to approximately $55^{\circ} \mathrm{C}$. Add the appropriate antibiotics $(100 \mu \mathrm{g} / \mathrm{ml}$ kanamycin or $100 \mu \mathrm{g} / \mathrm{ml}$ ampicillin) and pour the medium into $10 \mathrm{~cm}$ plates. Let the medium solidify and subsequently dry for approximately $10 \mathrm{~min}$. Store the plates at $4{ }^{\circ} \mathrm{C}$ until use.

9. LB medium: Dissolve $20 \mathrm{~g} \mathrm{NaCl}, 20 \mathrm{~g}$ tryptone, and $10 \mathrm{~g}$ yeast extract into $750 \mathrm{ml}$ water. Subsequently, fill up to $1 \mathrm{l}$ total volume and autoclave the solution. LB medium can be stored at room temperature. Prior to use, add $100 \mu \mathrm{g} / \mathrm{ml}$ kanamycin or $100 \mu \mathrm{g} / \mathrm{ml}$ ampicillin.

10. Plasmid DNA extraction kit.

\subsection{Mutagenesis}

PCR

1. High-fidelity DNA polymerase.

2. Forward and reverse primers for site-directed mutagenesis, containing the previously identified nucleotide substitution in the splice sites of interest ( see Note 3).

3. DpnI restriction enzyme.

\subsection{Cell Culture}

1. Zendo-1 cells (see Note 4 ).

2. L15 medium with L-glutamine (Sigma Aldrich, Saint Louis (MO), USA) ( see Note 5 ).

3. Fetal calf serum.

4. Penicillin-streptomycin.

5. Isoleucine.

6. Phosphate-buffered saline (PBS) $10 \times$ : Dissolve $8.1 \mathrm{~g} \mathrm{NaCl}$ (138 mM), $0.2 \mathrm{~g} \mathrm{KCl}(2.7 \mathrm{mM}), 1.15 \mathrm{~g} \mathrm{Na}_{2} \mathrm{HPO}_{4} \cdot 2 \mathrm{H}_{2} \mathrm{O}$ $(6.5 \mathrm{mM})$, and $0.2 \mathrm{~g} \mathrm{KH}_{2} \mathrm{PO}_{4}(1.5 \mathrm{mM})$ in 11 water. Adjust 


\subsection{RNA Isolation}

\section{6 cDNA Synthesis}

\subsection{Polymerase}

Chain Reaction

\subsection{Agarose Gel Electrophoresis}

\subsection{Donor Template Vector Design and Cloning}

$\mathrm{pH}$ to 7.4 with $\mathrm{HCl}$ and autoclave the solution. Dilute ten times with water before use. PBS can be stored at room temperature.

7. Trypsin 1:250. Dissolve $2.5 \mathrm{~g}$ trypsin in $100 \mathrm{ml} 10 \times \mathrm{PBS}$ and $900 \mathrm{ml}$ water. Sterilize by filtration.

8. Opti-MEM (Thermo Fisher Scientific, Carlsbad (CA), USA).

9. Liposome-based transfection reagent.

1. RNA isolation kit.

1. Reverse transcriptase.

2. Random Hexamers $(50 \mu \mathrm{M})$ (Thermo Fisher scientific, Carlsbad (CA), USA).

3. RNaseOUT'т Recombinant Ribonuclease Inhibitor (Thermo Fisher scientific, Carlsbad (CA), USA).

1. High-fidelity DNA polymerase.

2. dNTP mixture (10 mM each).

3. Target-specific forward and reverse primer (see Note 6).

1. Agarose-gel: Add $150 \mathrm{ml} 0.5 \times$ TBE buffer to $1.5 \mathrm{~g}$ of agarose, and boil the solution until the agarose is completely dissolved. Cool down to approximately $60{ }^{\circ} \mathrm{C}$ before adding ethidium bromide to a final concentration of $0.3 \mu \mathrm{g} / \mathrm{ml}$. Pour the gel into a gel-tray and let it solidify at room temperature (see Note 7).

1. Forward and reverse primers spanning the human sequence containing the (pseudo)exon of interest flanked by $>500 \mathrm{bp}$ up- and downstream intronic sequences.

2. Forward and reverse primers for the amplification of zebrafishspecific homology arms ( $900 \mathrm{bp})$ used for the homologous recombination reaction in zebrafish. Use the GeneArt ${ }^{\circledR}$ Primer and Construct Design Tool (https://www.thermofisher.com/ order/oligoDesigner/type2s) to design primers compatible with GeneArt ${ }^{\circledR}$ Type IIs Assembly Kit. The forward primer of the left homology arm and the reverse primer of the right homology arm should contain the sgRNA target site (see Note 8).

3. Gel and PCR Clean-up kit.

4. GeneArt ${ }^{\circledR}$ Seamless Cloning and Assembly Kit (Thermo Fisher Scientific, Waltham, MA, USA).

1. Tüpfel long fin (TL) zebrafish. 
2.11 CRISPR/Cas9 Injections
1. Glass microcapillaries.

2. Micropipette puller.

3. Microinjection plate: Add $80 \mathrm{ml}$ demineralized water to $0.8 \mathrm{~g}$ of agarose MP and boil the solution until the agarose is completely dissolved. Cool down to approximately $60{ }^{\circ} \mathrm{C}$ before pouring the gel into a dish. Cast the gel with a plastic mold that produces six 1.5-mm-wide trenches [10]. Let the gel solidify at room temperature.

4. Alt- ${ }^{\circledR}$ S.p. Cas9 Nuclease V3 (Integrated DNA Technologies, Coralville (IA), USA).

5. Potassium chloride.

6. Phenol red.

7. Pneumatic PicoPump pv820 (World Precision Instruments, Sarasota (FL), USA) with foot pedal or similar.

8. Stereo microscope with $10-40 \times$ magnification.

9. Micromaster Microscope Stage Micrometer $1 \mathrm{~mm}$ (Thermo Fisher Scientific, Waltham, MA, USA).

10. Mineral oil.

11. E3 embryo medium ( $5 \mathrm{mM} \mathrm{NaCl}, 0.17 \mathrm{mM} \mathrm{KCl}, 0.33 \mathrm{mM}$ $\mathrm{CaCl}_{2}, 0.33 \mathrm{mM} \mathrm{MgSO}_{4}$ ) supplemented with $0.1 \%$ methylene blue: Dissolve $34.8 \mathrm{~g} \mathrm{NaCl}, 1.6 \mathrm{~g} \mathrm{KCl}, 5.8 \mathrm{~g} \mathrm{CaCl}_{2}$, and $9.78 \mathrm{~g} \mathrm{MgCl}_{2}$ in $2 \mathrm{l}$ of demineralized water to prepare a $60 \times$ stock. Autoclave the $60 \times$ stock. To prepare $1 \times$ E3 medium, dilute $16.5 \mathrm{ml}$ of the $60 \times$ stock to 11 . Add $100 \mu \mathrm{l}$ of $1 \%$ methylene blue.

12. Zebrafish aquarium and spawning cages.

\subsection{Genotyping Materials}

2.13 Quantitative RTPCR

3. 1 M Tris- $\mathrm{HCl}$ (pH 7.5).
1. Lysis buffer $(40 \mathrm{mM} \mathrm{NaOH}$ and $0.2 \mathrm{mM}$ EDTA in ultrapure water).

2. 2-Phenoxyethanol.

4. Scissors and forceps.

5. PCR components.

1. Forward and reverse primers for the specific amplification of fragments with or without the human (pseudo)exon of interest, spanning about 100 bp of expected cDNA sequence (see Note 9).

2. gBlocks ${ }^{\circledR}$ Gene Fragments of the PCR targets (Integrated DNA Technologies, IA, USA).

3. Taq polymerase mix. 


\section{Methods}

\subsection{Splice Site Optimization}

1. The in silico "Berkeley Drosophila Genome Project" splice-site prediction tool (www.fruitfly.org/seq_tools/splice.html) can be used to analyze the strength of splice acceptor and donor sites, using standard settings ( see Note 10). Paste the nucleotide sequence of interest in FASTA format, starting the title line with " $>$." Use the submit button to see the resulting splice site prediction scores (see Note $1 \mathbf{1}$ ).

2. Compare the human splice acceptor and splice donor sequences of interest with the human and zebrafish splice-site consensus sequences [11] (Fig. la, b). Identify positions in the human splice acceptor and donor sequences of interest that are markedly different from the zebrafish consensus splice acceptor and donor sequences.

3. Adapt the human splice sites for increased recognition by the zebrafish splicing machinery by substituting nucleotides at the above identified positions in silico (see Note 12).

4. Analyze the in silico effect of the splice site adaptation(s) using the "Berkeley Drosophila Genome Project" splice-site prediction tool (Fig. 1b).

1. Perform a PCR using primers that contain Gateway ${ }^{\circledR}$-attB tails to generate a Gateway ${ }^{\circledR}$ cloning-compatible PCR amplicon containing the (pseudo)exon of interest flanked by $>500 \mathrm{bp}$ up- and downstream intronic sequences (see Notes 1, 2, and 13). Analyze the PCR products on an agarose gel. Extract and purify the PCR products by using a Gel and PCR Clean-up kit.

2. Perform a Gateway ${ }^{\circledR} \mathrm{BP}$-recombination reaction to generate an entry clone containing the purified PCR product. Mix $2 \mu \mathrm{l}$ of the BP clonase buffer, together with $150 \mathrm{ng}$ pDONR201 vector, $1 \mu \mathrm{l}$ of the recovered PCR product ( 15-150 ng), $4 \mu \mathrm{l}$ low TE buffer and $2 \mu$ Gateway $^{\circledR}$ BP clonase enzyme mix. Incubate the reaction at $25^{\circ} \mathrm{C}$ for $2 \mathrm{~h}$ (see Note 14$)$.

3. Terminate the Gateway ${ }^{\circledR} \mathrm{BP}$-cloning reaction by adding $\mathrm{l} \mu \mathrm{l}$ of the Proteinase K solution $(2 \mu \mathrm{g})$. Vortex briefly. Incubate sample at $37^{\circ} \mathrm{C}$ for $10 \mathrm{~min}$.

4. Transform $2.5 \mu$ of the BP reaction into $\mathrm{DH} 5 \alpha$ competent cells according to the manufacturer's instructions, and plate $200 \mu \mathrm{l}$ on LB agar plates that contain $100 \mu \mathrm{g} / \mathrm{ml}$ kanamycin as a selection marker for the pDONR201 vector. Incubate overnight at $37^{\circ} \mathrm{C}($ see Note $\mathbf{1 5})$.

5. Inoculate single colonies and culture them overnight in liquid LB medium supplemented with $100 \mu \mathrm{g} / \mathrm{ml}$ kanamycin (see Note 16). 
A splice donor site

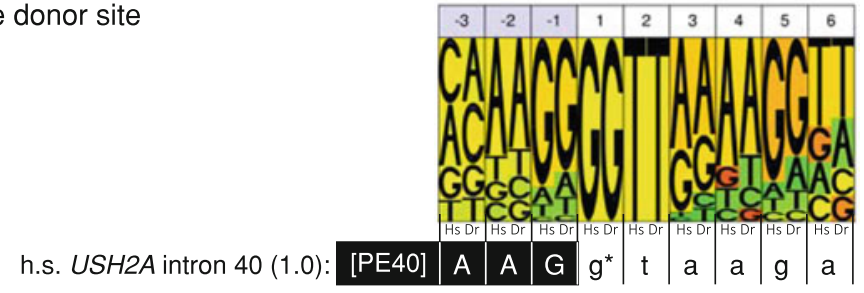

${ }^{*} \mathrm{C} .7595-2144 \mathrm{~A}>\mathrm{G}$

B splice acceptor site

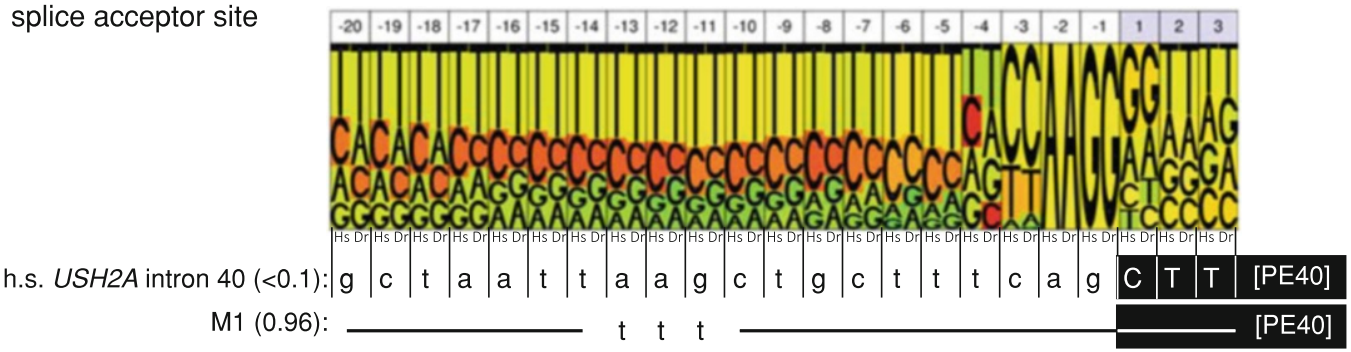

C

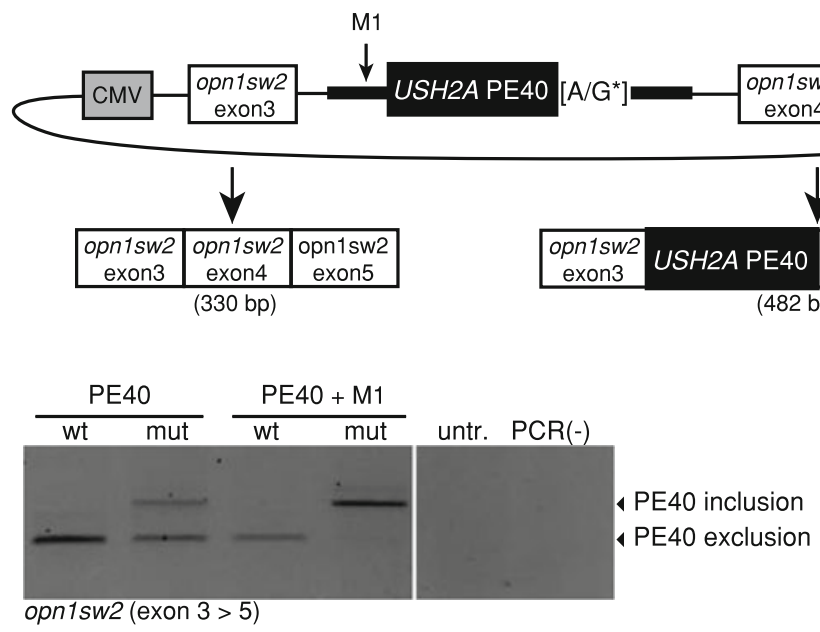

Fig. 1 Optimization of human USH2A PE40 splice acceptor site for improved recognition by the zebrafish splicing machinery. (a) The nucleotide distribution of the splice donor site found in man (Hs) and zebrafish (Dr). The PE40 splice donor sequence is presented under the splice donor sites with the c.7595-2144A > G mutation, indicated by an asterisk. (b) Similar as in (a), the PE40 splice acceptor sequence is presented under the consensus splice acceptor sites as used in human (Hs) and zebrafish (Dr). Based on comparisons, the M1 site was selected for optimization, predicted to result in a stronger PE40 splice acceptor site. The predicted strength of the splice acceptor site is indicated in brackets. (c) A zebrafish-specific minigene splice assay containing the human USH2A PE40 with flanking sequences was generated. The plasmids, either containing the c.7595-2144A > G mutation (mut) or not (wt), further contained M1 (indicated by vertical arrow). (d) The effect of the introduction of M1 on recognition of human USH2A PE40 after expression in zebrafish cells (Zendo-1) determined by RT-PCR. untr.: untransfected cells, PCR(-): negative template PCR control. (Reproduced from Slijkerman et al. [9], with permission from Mary Ann Liebert, Inc.)

6. Extract plasmid DNA from the bacterial cultures using a Plasmid DNA extraction kit. 


\subsection{Validation of the Optimized Splice Site Using an Engineered Zebrafish-Specific Minigene Splice Assay}

7. Validate the extracted plasmids by Sanger sequencing.

8. Perform mutagenesis PCR to introduce the previously identified nucleotide substitution in the splice sites of interest. Typically, one PCR $(50 \mu \mathrm{l})$ contains dNTPs (final concentration of $0.2 \mathrm{mM}$ for each nucleotide), forward and reverse primers containing the nucleotide substitution in the splice site of interest (final concentration of $0.2 \mathrm{mM}$ for each primer), $1 \mu \mathrm{l}$ (25-50 ng) entry clone, $0.5 \mu \mathrm{l}$ (1 unit) high-fidelity DNA polymerase, and $10 \mu \mathrm{l} 5 \times$ reaction buffer. Cycling conditions are: $95^{\circ} \mathrm{C}$ for $5 \mathrm{~min}$, followed by 15 cycles with $95^{\circ} \mathrm{C}$ for $30 \mathrm{~s}$, “Tm" ${ }^{\circ} \mathrm{C}$ for $1 \mathrm{~min}$ and $68{ }^{\circ} \mathrm{C}$ for $6 \mathrm{~min}$. The “Tm" temperature depends on the primers used and should be optimized on beforehand. The reaction is finalized by a 5 -min incubation step at $68{ }^{\circ} \mathrm{C}$ after which the reaction is cooled down to $16{ }^{\circ} \mathrm{C}$ until further processing.

9. Analyze the PCR products on an agarose gel.

10. Digest the PCR product with DpnI (see Note 17).

11. Repeat steps 4-7 in order to obtain the entry clone with optimized splice site ( see Note 18).

12. Perform a Gateway ${ }^{\circledR}$ LR-recombination reaction to generate a pCI-neo-based zebrafish-specific minigene splice vector. Mix $2 \mu \mathrm{LR}$ clonase buffer with $150 \mathrm{ng}$ of the entry clone, $150 \mathrm{ng}$ pCI-neo-opn 1sw 2 exon3-5 destination vector, $2 \mu$ Gateway $^{\mathbb{R}}$ LR clonase enzyme mix and low TE buffer to a final volume of $10 \mu$. Incubate the reaction at $25^{\circ} \mathrm{C}$ for $2 \mathrm{~h}$ ( see Note 14).

13. Repeat steps $3-7$, using ampicillin instead of kanamycin, in order to obtain the desired zebrafish-specific pCI-neo-based minigene splice vector (Fig. 1c).

1. Culture Zendo- 1 cells at $28^{\circ} \mathrm{C}$. Passage them twice a week in a $1: 4$ dilution using trypsin (see Notes 4, 5, and 19).

2. Seed $1.0 \times 10^{6}$ cells/well into a six-well plate 1 day before transfection ( see Note 20 ).

3. Transfect zebrafish-specific pCI-neo-based minigene splice vector into the Zendo- 1 cells. Prepare a Lipofectamine ${ }^{\circledR} 2000$ $(5 \mu \mathrm{l}) /$ Opti-MEM $(250 \mu \mathrm{l})$ mixture and a DNA vector $(1 \mu \mathrm{g}) /$ Opti-MEM $(250 \mu \mathrm{l})$ mixture. Incubate both mixtures at room temperature for $5 \mathrm{~min}$ before adding them together. Incubate the combined mixture at room temperature for $10 \mathrm{~min}$ before adding them drop-wise to the cells ( see Note 21).

4. Remove the culture medium 4-6 h after transfection and add fresh L15 medium to the cells.

5. Approximately $48 \mathrm{~h}$ after transfection, wash the cell with PBS and collect them by using a cell scraper. Centrifuge the cells at 
$234 \times g$ for $5 \mathrm{~min}$. Isolate total RNA using a RNA isolation kit, according to manufacturer's instructions.

6. Use $100 \mathrm{ng}$ to $1 \mu \mathrm{g}$ of total RNA for cDNA synthesis using Reverse Transcriptase. Prepare a tube for primer annealing and combine $100 \mathrm{ng}$ total RNA, $1 \mu \mathrm{l}$ random hexamers $(50 \mu \mathrm{M})$, $1 \mu \mathrm{dNTP} \operatorname{mix}(10 \mathrm{mM})$ and fill up till $13 \mu \mathrm{l}$ with nuclease-free water. Incubate the mixture at $65^{\circ} \mathrm{C}$ for 5 min before placing it on ice for at least $1 \mathrm{~min}$. Prepare in a second tube a mixture consisting of $4 \mu \mathrm{l} 5 \times$ SSIV buffer, $1 \mu \mathrm{l} 100 \mathrm{mM} \mathrm{DTT}, 1 \mu \mathrm{l}$ RNaseOUT ${ }^{\text {TM }}$ Recombinant Ribonuclease Inhibitor and $1 \mu \mathrm{l}$ Reverse Transcriptase $(200 \mathrm{U} / \mu \mathrm{l})$. Add the mixture to the annealed primers and incubate the complete reaction mixture at $23{ }^{\circ} \mathrm{C}$ for $10 \mathrm{~min}, 55^{\circ} \mathrm{C}$ for $50 \mathrm{~min}$ and $80^{\circ} \mathrm{C}$ for $10 \mathrm{~min}$.

7. Depending on the RNA input, the cDNA product generated after the reverse transcriptase reaction can be diluted up to $20 \times$ to serve as a template in a PCR. Typically, one PCR $(25 \mu \mathrm{l})$ contains dNTPs (final concentration of $0.2 \mathrm{mM}$ for each nucleotide), forward and reverse primers (final concentration of $0.2 \mathrm{mM}$ for each primer), 0.5-1 $\mu \mathrm{l}(25-50 \mathrm{ng}) \mathrm{cDNA}$, $0.25 \mu \mathrm{l}(0.5$ units $)$ DNA polymerase, and $5 \mu \mathrm{l} 5 \times$ reaction buffer. Cycling conditions are: $98{ }^{\circ} \mathrm{C}$ for $1 \mathrm{~min}$, followed by 30 cycles with $98{ }^{\circ} \mathrm{C}$ for $20 \mathrm{~s}$, “Tm" ${ }^{\circ} \mathrm{C}$ for $20 \mathrm{~s}$ and $72{ }^{\circ} \mathrm{C}$ for $1 \mathrm{~min}$. The "Tm" temperature depends on the primers used and should be optimized on beforehand. The reaction is finalized by a 5 -min incubation step at $72{ }^{\circ} \mathrm{C}$ after which the reaction is cooled down to $16{ }^{\circ} \mathrm{C}$ until further processing.

8. Analyze the PCR products on an agarose gel. RT-qPCR is recommended when quantification of transcripts is desired to determine the effect of the optimized splice sites. Figure ld shows the improved recognition of the human PE40 exon in zebrafish after the introduction of the Ml variant in the splice acceptor site.

\subsection{Guide RNA Design for CRISPR/ Cas9 Injection}

1. Determine the landing site of a given human (pseudo)exon within (the appropriate intronic region of) the corresponding zebrafish gene by using a sequence assembly tool (https:// genome.ucsc.edu/cgi-bin/hgBlat?command=start). The zebrafish sequence with the highest homology will be exchanged for the human target sequence.

2. The online webtool CHOPCHOP (https://chopchop.cbu. uib.no/) can be used to identify candidate Cas9 target sites within the identified zebrafish genomic region of interest and to design corresponding guide RNAs, using standard settings. Select "Paste target" and paste the sequence of interest in FASTA format. Use the "Find Target Sites!" button to predict the Cas9 target sites in your sequence of interest (see Note 22). 


\subsection{Generation of Donor Template for CRISPR/Cas9-Induced Homology Directed DNA Repair}

3. Select and order the custom guide RNA with no predicted off target binding to other genomic regions (see Note 23).

1. Amplify the human (pseudo)exon of interest with optimized splice sites and surrounding sequences (see Note 24). Extract and purify the amplified PCR product from an agarose gel using a Gel and PCR Clean-up kit.

2. Design and amplify the left and right homology arm using zebrafish genomic DNA as a template. Homology arms of 900 bp flanking the target region have shown to be very effective $[9,12]$. Extract and purify the PCR products from an agarose gel using a Gel and PCR Clean-up kit.

3. Make use of the GeneArt ${ }^{\circledR}$ Seamless Cloning and Assembly Kit to combine the in steps $\mathbf{1}$ and $\mathbf{2}$ amplified PCR products with the supplied linearized pUC19L vector in order to generate a donor template construct containing the human sequence with optimized splice sites flanked by two zebrafish homology arms and sgRNA target sites.

4. Transform $2.5 \mu \mathrm{l}$ of the GeneArt ${ }^{\circledR}$ assembly reaction into DH5 $\alpha$ competent cells and plate $200 \mu \mathrm{l}$ on LB agar plates that contain $100 \mu \mathrm{g} / \mathrm{ml}$ ampicillin as a selection marker for the pUC19 vector. Incubate overnight at $37^{\circ} \mathrm{C}($ see Note 15).

5. Inoculate single colonies and culture them overnight in liquid LB medium supplemented with $100 \mu \mathrm{g} / \mathrm{ml}$ ampicillin (see Note 16).

6. Extract plasmid DNA from the bacterial cultures using a DNA extraction kit followed by a phenol/chloroform/isoamyl (25: 24:1) extraction and ethanol precipitation.

7. Sanger sequencing verification of the donor template construct.

3.6 Generation of the Humanized Zebrafish Line
1. Use a micropipette puller to prepare glass injection needles from microcapillaries (see Note 25).

2. Prepare a microinjection plate by casting a $1 \%$ agarose gel using a plastic mold that produces six $1.5-\mathrm{mm}$-wide trenches (see Note 26).

3. Prepare the injection mixture by combining Cas9 protein $(800 \mathrm{ng} / \mu \mathrm{l})$, sgRNA $(100 \mathrm{ng} / \mu \mathrm{l})$, potassium chloride $(0.3 \mathrm{M})$, phenol red $(0.1 \%)$, and donor template DNA (25 pg) (see Note 27). Incubate injection mixture at $37{ }^{\circ} \mathrm{C}$ for 5 min prior to injections (see Note 28).

4. Perform injections by using a Pneumatic Picopump pv280 microinjector, a pipette holder, a foot pedal, and a stereoscope or similar (see Note 29) (see Note 30). Load the injection needle with injection mixture and calibrate the needle by 
adjusting the pressure and time settings of the microinjector until the injection volume is $1 \mathrm{nl}$ (see Note 31).

5. Align single-cell-staged fertilized eggs in the trenches of the microinjection plate.

6. Inject embryos by piercing the cell membrane with the injection needle. Press the foot pedal to inject $1 \mathrm{nl}$ of the injection mixture into the cell.

7. Transfer embryos to a new dish containing fresh E3 medium after injection and raise them at $28{ }^{\circ} \mathrm{C}$. Refresh E3 medium on a daily basis and remove dead embryos (see Note 32 ).

8. At $5 \mathrm{dpf}$, transfer the embryos from the dish to a tank in the zebrafish aquarium and raise them for 3 months. At 3 months post-fertilization the injected fish (F0 generation) are sexually mature and can be crossed [13]. The offspring of these F0 fish can be sacrificed for germline transmission analysis of the anticipated recombination event. When positive, Fl of the germlinepositive founder fish can be raised for 3 months, and genotyped to identify heterozygous knock-in animals.

3.7 Genotyping After Fin Clipping
1. Prepare for each adult fish one PCR tube containing $75 \mu \mathrm{l}$ of lysis buffer and one single box containing 11 of fresh water.

2. Prepare an anesthetic by mixing $250 \mu \mathrm{l} 2$-phenoxyethanol with $500 \mathrm{ml}$ water in a beaker.

3. Anesthetize adult zebrafish by putting them in the 2-phenoxyethanol solution for 1-2 min.

4. Manually pick up the anesthetized fish and use scissors to cut a small piece of the caudal fin. Quickly put the fish back into a single box with fresh water. Put the fin in a properly labeled PCR tube using clean forceps. Make sure that both the single box and the PCR tube are labeled with the same number (see Notes 33 and 34).

5. Incubate the PCR tubes at $95^{\circ} \mathrm{C}$ for $20 \mathrm{~min}$ ( see Note 35 ).

6. Add $7.5 \mu \mathrm{l}(10 \%) 1 \mathrm{M}$ Tris- $\mathrm{HCl}(\mathrm{pH} 7.5)$ to the lysate (see Note 36).

7. Dilute the lysate ten times with sterile water and use it directly as a template in a PCR. Typically, one PCR $(25 \mu \mathrm{l})$ contains dNTPs (final concentration of $0.2 \mathrm{mM}$ for each nucleotide), forward and reverse primers (final concentration of $0.2 \mathrm{mM}$ for each primer), $1 \mu$ lysate, $0.25 \mu \mathrm{l}$ (0.5 units) DNA polymerase, and $5 \mu \mathrm{l} 5 \times$ reaction buffer. Cycling conditions are: $98^{\circ} \mathrm{C}$ for $2 \mathrm{~min}$, followed by 30 cycles with $98{ }^{\circ} \mathrm{C}$ for $20 \mathrm{~s}$, “Tm” ${ }^{\circ} \mathrm{C}$ for $20 \mathrm{~s}$, and $72{ }^{\circ} \mathrm{C}$ for $1 \mathrm{~min}$. The "Tm" temperature depends on the primers used and should be optimized on beforehand. The reaction is finalized by a 5 -min incubation step at $72{ }^{\circ} \mathrm{C}$ after 


\subsection{Visualization of Human (Pseudo)Exon Inclusion in Zebrafish}

3.9 Quantification of Human (Pseudo)Exon Inclusion Using Quantitative RT-PCR (RT-qPCR) which the reaction is cooled down to $16{ }^{\circ} \mathrm{C}$ until further processing.

8. Analyze the PCR products on an agarose gel. Confirm the presence or absence of the (pseudo)exon by Sanger sequencing.

1. Snap freeze $5 \mathrm{dpf}$ larvae in liquid nitrogen and isolate total RNA using an RNA isolation kit.

2. Synthesize cDNA using Reverse Transcriptase. Prepare a tube for primer annealing and combine $100 \mathrm{ng}$ total RNA, l $\mu \mathrm{l}$ random hexamers $(50 \mu \mathrm{M}), 1 \mu \mathrm{dNTP}$ mix $(10 \mathrm{mM})$ and fill up till $13 \mu \mathrm{l}$ with nuclease-free water. Incubate the mixture at $65{ }^{\circ} \mathrm{C}$ for $5 \mathrm{~min}$ before placing it on ice for at least $1 \mathrm{~min}$. Prepare in a second tube a mixture consisting of $4 \mu \mathrm{l} 5 \times$ SSIV buffer, $1 \mu \mathrm{l} 100 \mathrm{mM}$ DTT, $1 \mu \mathrm{l}$ RNaseOUT ${ }^{\mathrm{TM}}$ Recombinant Ribonuclease Inhibitor, and $1 \mu \mathrm{l}$ Reverse Transcriptase $(200 \mathrm{U} / \mu \mathrm{l})$. Add the mixture to the annealed primers and incubate the complete reaction mixture at $23{ }^{\circ} \mathrm{C}$ for $10 \mathrm{~min}$, $55^{\circ} \mathrm{C}$ for $50 \mathrm{~min}$, and $80^{\circ} \mathrm{C}$ for $10 \mathrm{~min}$.

3. Dilute your synthesized cDNA $2-10 \times$ (depending on gene expression levels) and use it as a template for PCR amplification. Typically, one PCR $(20 \mu \mathrm{l})$ contains dNTPs (final concentration of $0.2 \mathrm{mM}$ for each nucleotide), forward and reverse primers (final concentration of $0.2 \mathrm{mM}$ for each primer), $1 \mu \mathrm{l}$ $2-10 \times$ diluted cDNA, $0.25 \mu \mathrm{l}$ (0.5 units) DNA polymerase, and $4 \mu \mathrm{l} 5 \times$ reaction buffer (see Note 6 ). Cycling conditions are: $98{ }^{\circ} \mathrm{C}$ for $2 \mathrm{~min}$, followed by 35 cycles with $98{ }^{\circ} \mathrm{C}$ for $15 \mathrm{~s}$, “Tm" ${ }^{\circ} \mathrm{C}$ for $20 \mathrm{~s}$, and $72{ }^{\circ} \mathrm{C}$ for $45 \mathrm{~s}$. The "Tm" temperature depends on the primers used and should be optimized on beforehand. The reaction is finalized by a 5 -min incubation step at $72{ }^{\circ} \mathrm{C}$ after which the reaction is cooled down to $16{ }^{\circ} \mathrm{C}$ until further processing.

4. Visualize human (pseudo)exon inclusion by analyzing the amplified PCR products on an agarose gel. Figure $2 \mathrm{a}$ shows an example of increased in vivo recognition of the (pseudo)exon after optimization of the splice site.

1. Order two gBlocks ${ }^{\circledR}$ Gene Fragments, one for each of the RT-qPCR amplicons (see Note 37). These synthetic oligonucleotides can be used to generate a standard curve of known copy numbers for each amplicon. Dissolve the gBlocks ${ }^{\circledR}$ Gene Fragments and prepare a stock solution containing $10^{7}$ copies per $\mu$ ( see Note 38). Generate a 1:1 serial dilution series of the gBlock $^{\circledR}$ stock solution in cDNA of an unrelated species (see Note 39). 


\section{A}
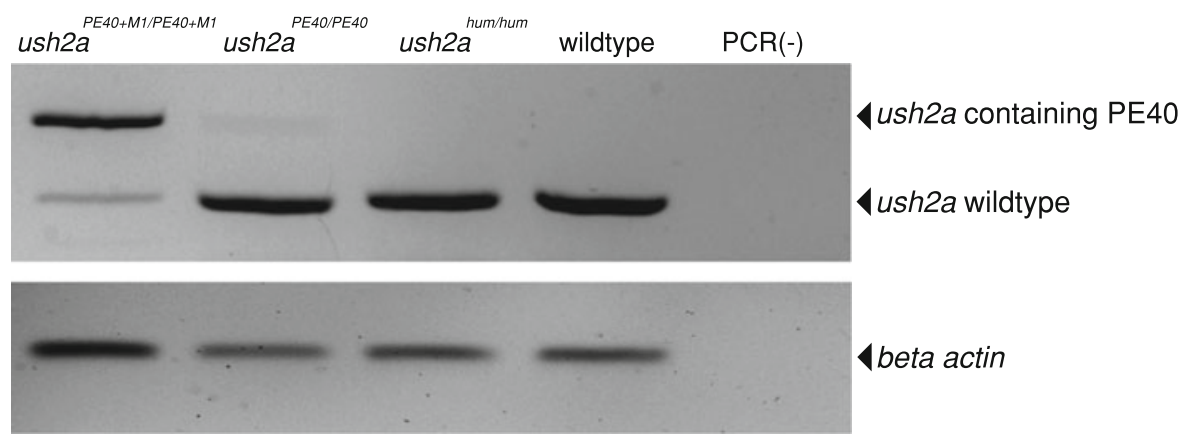

B Quantification of ush2a PE40 transcripts

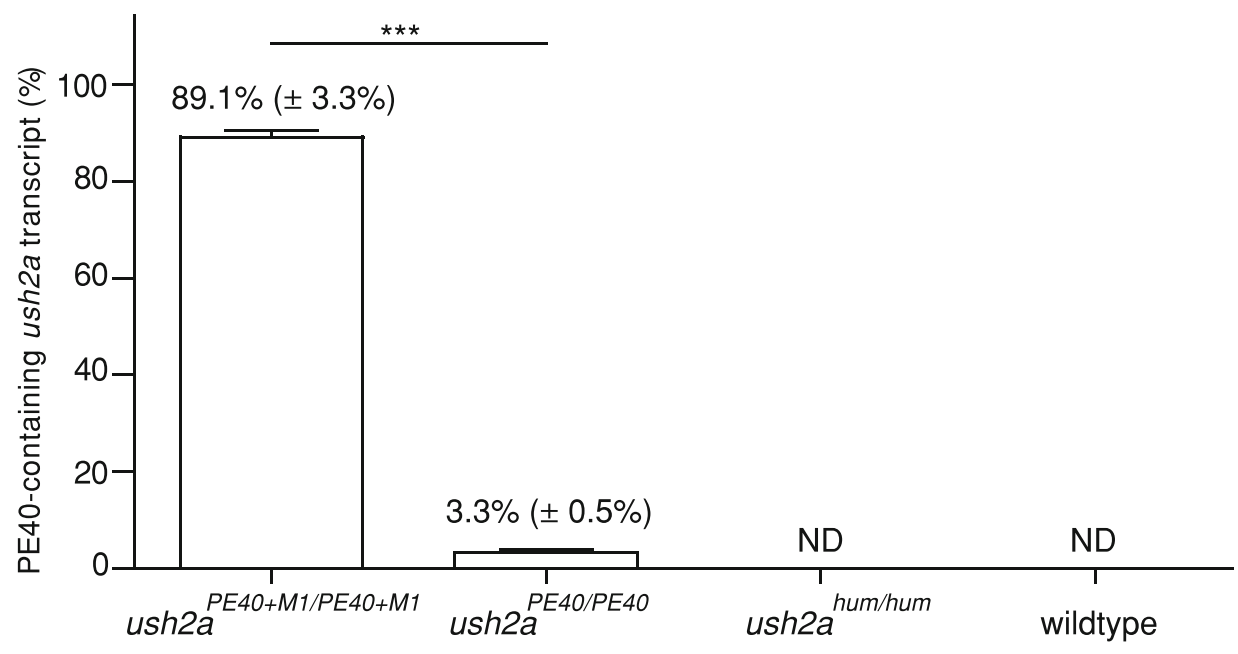

Fig. 2 Human USH2A PE40 incorporation in zebrafish ush2a transcripts. (a) The level of human USH2A PE40 incorporation into the zebrafish ush2a transcript is analyzed by RT-PCR using cDNA derived from ush2$a^{P E 40+M 1 / P E 40+M 1}$, ush2a $a^{P E 40 / P E 40}$, ush2a $a^{\text {hum/hum }}$, and wild-type larvae (5dpf). Beta actin amplification is shown as loading control (lower panel). (b) Quantitative RT-PCR analyses to determine the absolute number of PE40-containing ush2a transcripts in ush2a $a^{P E 40+M 1 / P E 40+M 1}$, ush2a ${ }^{P E 40 / P E 40}$, ush2a ${ }^{\text {hum/hum }}$, and wild-type larvae (5dpf). Data are expressed as percentage of PE40-inclusion (mean $\pm \mathrm{SD}$ ). Two-tailed unpaired Student's $t$-test revealed significant differences between groups $(p=0.0001)$. ND not detectable

2. Perform a RT-qPCR with a primer pair designed to specifically amplify the exon-inclusion amplicon and a RT-qPCR with a primer pair designed to specifically amplify the exon-exclusion amplicon on the serial gBlocks ${ }^{\circledR}$ dilution and on the zebrafish cDNA samples ( see Note 9). Amplify all amplicons in duplicate.

3. Analyze the RT-qPCR data by plotting a standard curve of the $\log$ values of the copy numbers of the gBlock dilutions against the mean cycle quantification value (Ct or Cq) measured for each gBlock dilution (see Note 40). Based on the standard curve, calculate for each cDNA sample, the transcript number 
of the exon-inclusion amplicon and of the exon-exclusion amplicon. The amount of product expected from splice site optimization can be calculated as percentage of total $u s h 2 a$ transcripts (Fig. 2b). The latter can be calculated as the sum of wild-type product and product expected from splice site optimization ( see Note 41).

\section{Notes}

1. Design a forward and reverse primer to generate the amplicon with the sequence of interest. Add a Gateway ${ }^{\circledR}$-compatible attBl tail to the forward primer (5'-GGGGACAAGTTTGTA CAAAAAAGCAGGCT-XXX-3') and attB2 tail to the reverse primer (5'- GGGGACCACTTTGTACAAGAAAGCTGGGT YYY- $\left.3^{\prime}\right)$. XXX indicates the forward primer sequence and YYY indicates the reverse primer sequence from $5^{\prime}$ to $3^{\prime}$.

2. The advised maximum fragment size for Gateway cloning reactions is $8 \mathrm{~kb}$.

3. Typically, mutagenesis primers have a length of $25-45$ nucleotides with the anticipated mutation in the center. The melting temperature (Tm) must be $\geq 78{ }^{\circ} \mathrm{C}$ and a $\mathrm{G}$ or $\mathrm{C}$ base at the $3^{\prime}$ end of each primer is favored, due to the higher stability of GC base pairs (three hydrogen bonds) as compared to AT base pairs (two hydrogen bonds).

4. Use a zebrafish-specific cell line that does not endogenously express the gene of interest (in this case opn Isw2). Endogenous expression of the gene of interest can interfere with the analysis of the effect of the mutation on splicing. A detailed protocol for the generation of your own zebrafish-specific cell line is described by Choorapoikayil et al. [14].

5. Culture Zendo- $\mathrm{l}$ cells at $28{ }^{\circ} \mathrm{C}$ in $\mathrm{L} 15$ medium supplemented with $15 \% \mathrm{v} / \mathrm{v}$ FCS, $1 \% \mathrm{v} / \mathrm{v}$ penicillin/streptomycin and $250 \mathrm{mg} / \mathrm{l}$ isoleucine (final concentration in the medium). All cell culture reagents should be pre-warmed to the same temperature as at which the cells are cultured.

6. The total PCR amplicon length should be chosen in such a way that splice redirection results in a markedly different-sized PCR product that can be readily distinguished after agarose gel electrophoresis. The inclusion of multiple flanking exons in the minigene splice assay is of importance since sequence alterations can not only influence the in- and exclusion of the targeted (pseudo)exon but also induce the in- and exclusion of flanking exons [15]. 
7. Casted agarose gels can be stored at $4{ }^{\circ} \mathrm{C}$ for up to 1 month when properly sealed in order to prevent them from drying out.

8. Adding the sgRNA target site to your donor template was found to increase the desired knock-in event up to 20-fold compared to using a donor template vector without those sites [12]. Note that the introduced sgRNA target site should include a canonical PAM site.

9. To specifically amplify transcripts without the target exon, one of the primers must span the exon-exon boundary of the surrounding exons. For the detection of the exon-inclusion transcript, one of the primers must reside within the target exon. Alternatively, custom TaqMan ${ }^{\circledR}$ assays (Thermo Fisher scientific, Carlsbad (CA), USA) can be designed for each transcript.

10. The strength of a splice site is conditioned to many different factors, like splice site sequence, the strength of competing splice sites, the relative positions of splice sites, and the presence of tissue-specific trans-acting factors [16]. The in silico calculated strength is therefore stochastic.

11. Splice site prediction scores can range from 0 (extremely weak) to 1.0 (extremely strong). Optimize a given splice donor or acceptor site to reach a prediction score as close as possible to 1.0. Keep in mind not to alter the sequence of potential antisense oligonucleotide binding sites.

12. Avoid (pseudo)exonic nucleotide substitutions, since those substitutions can result in changes in the encoded amino acids and can potentially affect AON binding sites.

13. Use a high-fidelity DNA polymerase (e.g., Q5 ${ }^{\circledR}$ High-Fidelity DNA Polymerase). High-fidelity DNA polymerases couple low misincorporation rates with proofreading activity, resulting in near-perfect replication of the target DNA and thereby efficient cloning of the plasmids.

14. We have experienced that extending the incubation time at $25^{\circ} \mathrm{C}$ from 2 h to overnight greatly improves the recombination efficiency for difficult cloning reactions (e.g., larger fragments to be cloned).

15. In case no transformants are obtained using $\mathrm{DH} 5 \alpha$ competent cells, one can consider the use of competent cells with a higher transformation efficiency (e.g., TOP10 competent cells).

16. As a rule of thumb, we generally analyze three clones per reaction.

17. DpnI cleaves only methylated recognition sites. It will therefore only cleave the bacterial template DNA and not the amplified DNA. 
18. Skip steps 8-11 to obtain the splice vector without optimized splice sites. Depending on the predicted strengths of the splice sites, it can be useful to first investigate pre-mRNA splicing in a construct without splice site optimization.

19. We culture Zendo- 1 cells at $28^{\circ} \mathrm{C}$ since they are derived from zebrafish which thrive at an ambient temperature of $28^{\circ} \mathrm{C}$.

20. Seeding density depends on the type of zebrafish-derived cells that are used. Seed cells to be $70-90 \%$ confluent at the time of transfection.

21. The two-step dilution method results in higher quality data and generates more reproducible results compared to adding the lipid directly to the diluted DNA. The 10-min pre-incubation stimulates the formation of micelles containing plasmid DNA prior to transfection, resulting in the highest transfection efficiency.

22. The requirement of an NGG PAM site at the target sequence can limit applications of frequently used Cas9 from Streptococcus pyogenes. Depending on the target region, other RNA-guided endonucleases can be used, each targeting a unique PAM sequence [17].

23. Single guide RNAs can also be produced manually according to the protocol published by Gagnon et al. [18].

24. Also generate a donor template construct without optimization of the splice sites. This construct can be used as a control to analyze the effect of the splice site optimization.

25. Micropipette puller programs for preparation of injection needles differ between machines and installed heating filaments and should be experimentally optimized according to the device manual.

26. Microinjection plates can be used multiple times upon storage at $4{ }^{\circ} \mathrm{C}$ for up to 1 month.

27. Phenol red is added to the injection mixture as a tracer to show which embryo received a dose.

28. Pre-incubation at $37{ }^{\circ} \mathrm{C}$ induces Cas $9 / \mathrm{sgRNA}$ complex formation.

29. The Pneumatic Picopump pv280 microinjector delivers precise volume through pressure pulses of air, which can be adjusted by the user. A foot pedal is connected to the injector and activates the pressure pulse for injection mix delivery. The pipette holder secures the pipette for use during the procedure and connects it to the airline of the injector.

30. A micromanipulator can be used for micro-injections. It allows the researcher to make small and accurate adjustments to the pipette location. However, our experience suggests manual 
microinjection since it results in a higher injection speed and accuracy.

31. To calculate the volume of a sphere, use the following formula: Volume of a sphere $\left(\mathrm{cm}^{3}\right)=4 / 3 \pi r^{3}(r$ in $\mathrm{cm})$. A $1 \mathrm{nl}$ sphere is $1 \times 10^{-6} \mathrm{~cm}^{3}$. Define the radius of the sphere by using a calibration micrometer.

32. To get an indication of the recombination efficiency, a selection of embryos ( 15 embryos) can be sacrificed at 1 day post fertilization for genotyping purposes. Lyse and genotype the embryos individually as described in Subheading 3.8.

33. Fish can be kept in single boxes for a maximum of 5 days without feeding and flow of fresh water, although guidelines and legislation concerning housing can differ between institutions. Consult your local institutional guidelines for the most accurate information.

34. Check if all tails are immersed in the lysis buffer.

35. Flick the PCR tubes to mix and disintegrate the tissue.

36. Tris- $\mathrm{HCl}$ neutralizes the lysis buffer and stabilizes DNA, thereby supporting long-term storage.

37. gBlocks $^{\circledR}$ Gene Fragments are affordable and easy to obtain. Using gBlock fragments as DNA standards in a RT-qPCR assay decreases time, reagents, and costs of creating a standard curve [19].

38. Use the mass of the gBlocks fragments (provided by manufacturer) to calculate the amount of DNA copies in the gBlock standard by using the following formula: weight per copy $=(\#$ bp in gBlocks $) \times 617.5 \mathrm{~g} / \mathrm{mol} / \mathrm{bp} \times\left(1 \mathrm{~mol} / 6.02 \times 10^{23}\right.$ molecules) [19].

39. Diluting the gBlock in cDNA of an unrelated species provides a cDNA context in which off-target binding of the primers is included in the RT-qPCR efficiency, without the presence of on-target transcripts.

40. Adjust the gBlock dilution range if amplification of the used gBlock dilution series did result in amplification values outside of the qPCR detection range.

41. A third primer pair and gBlock can be used to quantify the total number of transcripts by amplifying other exons of the transcript.

The authors would like to thank Dr. Jeroen den Hertog for sharing his zebrafish cell line Zendo-1. The authors acknowledge the 
facilities and personnel of the Zebrafish Facility at the Faculty of Science of the Radboud University Nijmegen. The authors received funding from the Foundation Fighting Blindness USA (FFB PPA-0517-0717-RAD to EvW) and Stichting Ushersyndroom (to EvW and EdV) for the research that led to the protocol.

\section{References}

1. Liu MM, Zack DJ (2013) Alternative splicing and retinal degeneration. Clin Genet 84: 142-149. https://doi.org/10.1111/cge. 12181

2. Cremers FP, van de Pol DJ, van Driel M et al (1998) Autosomal recessive retinitis pigmentosa and cone-rod dystrophy caused by splice site mutations in the Stargardt's disease gene ABCR. Hum Mol Genet 7:355-362. https:// doi.org/10.1093/hmg/7.3.355

3. Hollander den AI, Koenekoop RK, Yzer S et al (2006) Mutations in the CEP290 (NPHP6) gene are a frequent cause of Leber congenital amaurosis. Am J Hum Genet 79:556-561. https://doi.org/10.1086/507318

4. Thompson DA, Gyürüs P, Fleischer LL et al (2000) Genetics and phenotypes of RPE65 mutations in inherited retinal degeneration. Invest Ophthalmol Vis Sci 41:4293-4299

5. Vaché C, Besnard T, le Berre P et al (2012) Usher syndrome type 2 caused by activation of an USH2A pseudoexon: implications for diagnosis and therapy. Hum Mutat 33:104-108. https://doi.org/10.1002/humu.21634

6. Hammond SM, Wood MJA (2011) Genetic therapies for RNA mis-splicing diseases. Trends Genet 27:196-205. https://doi.org/10. 1016/j.tig.2011.02.004

7. Slijkerman RWN, Song F, Astuti GDN et al (2015) The pros and cons of vertebrate animal models for functional and therapeutic research on inherited retinal dystrophies. Prog Retin Eye Res 48:137-159. https://doi.org/10. 1016/j.preteyeres.2015.04.004

8. Garanto A, van Beersum SEC, Peters TA et al (2013) Unexpected CEP290 mRNA splicing in a humanized knock-in mouse model for Leber congenital amaurosis. PLoS One 8: e79369. https://doi.org/10.1371/journal. pone.0079369

9. Slijkerman R, Goloborodko A, Broekman S et al (2018) Poor splice-site recognition in a humanized zebrafish knockin model for the recurrent deep-Intronic c.7595-2144A $>\mathrm{G}$ mutation in USH2A. Zebrafish 15:597. https://doi.org/10.1089/zeb.2018.1613
10. Westerfield M (2000) The zebrafish book : a guide for the laboratory use of zebrafish. http://zfin.org/zf_info/zfbook/zfbk.html

11. Abril JF, Castelo R, Guigó R (2005) Comparison of splice sites in mammals and chicken. Genome Res 15:111-119. https://doi.org/ $10.1101 / \mathrm{gr} .3108805$

12. Irion U, Krauss J, Nüsslein-Volhard C (2014) Precise and efficient genome editing in zebrafish using the CRISPR/Cas9 system. Development 141:4827-4830. https://doi.org/10. 1242/dev. 115584

13. Singleman C, Holtzman NG (2014) Growth and maturation in the zebrafish, Danio rerio: a staging tool for teaching and research. Zebrafish 11:396-406. https://doi.org/10.1089/ zeb. 2014.0976

14. Choorapoikayil S, Overvoorde J, Hertog den J (2013) Deriving cell lines from zebrafish embryos and tumors. Zebrafish 10:316-325. https://doi.org/10.1089/zeb.2013.0866

15. Lenassi E, Saihan Z, Bitner-Glindzicz M, Webster AR (2014) The effect of the common c. $2299 \mathrm{delG}$ mutation in USH2A on RNA splicing. Exp Eye Res 122:9-12. https://doi. org/10.1016/j.exer.2014.02.018

16. Fu XY, Manley JL (1987) Factors influencing alternative splice site utilization in vivo. Mol Cell Biol 7:738-748. https://doi.org/10. $1128 / \mathrm{mcb} .7 .2 .738$

17. Yao R, Liu D, Jia X et al (2018) CRISPRCas9/Cas12a biotechnology and application in bacteria. Synth Syst Biotechnol 3:135-149. https://doi.org/10.1016/j.synbio.2018. 09.004

18. Gagnon JA, Valen E, Thyme SB et al (2014) Efficient mutagenesis by Cas9 proteinmediated oligonucleotide insertion and largescale assessment of single-guide RNAs. PLoS One 9:e98186. https://doi.org/10.1371/ journal.pone.0098186

19. Conte J, Potoczniak MJ, Tobe SS (2018) Using synthetic oligonucleotides as standards in probe-based qPCR. BioTechniques 64: 177-179. https://doi.org/10.2144/btn2018-2000 
Open Access This chapter is licensed under the terms of the Creative Commons Attribution 4.0 International License (http://creativecommons.org/licenses/by/4.0/), which permits use, sharing, adaptation, distribution and reproduction in any medium or format, as long as you give appropriate credit to the original author(s) and the source, provide a link to the Creative Commons license and indicate if changes were made.

The images or other third party material in this chapter are included in the chapter's Creative Commons license, unless indicated otherwise in a credit line to the material. If material is not included in the chapter's Creative Commons license and your intended use is not permitted by statutory regulation or exceeds the permitted use, you will need to obtain permission directly from the copyright holder. 